\title{
Expression of chemokine receptor CXCR4 in nasopharyngeal carcinoma: pattern of expression and correlation with clinical outcome
}

\author{
Na Wang1,2, Qiu-Liang Wu ${ }^{1,3}$, Yan Fang1,2, Hai-Qiang Mai1,4, Mu- \\ Sheng Zeng1,2, Guo-Ping Shen ${ }^{1,2}$, Jing-Hui Hou ${ }^{1,3}$ and Yi-Xin Zeng*1,2
}

\begin{abstract}
Address: ${ }^{1}$ State Key Laboratory of Oncology in Southern China, ${ }^{2}$ Department of Experimental Research, Cancer Center, Sun Yat-sen University, Guangzhou 510060, China, ${ }^{3}$ Department of Pathology, Cancer Center, Sun Yat-sen University, Guangzhou 510060, China and ${ }^{4}$ Department of Nasopharyngeal Carcinoma, Cancer Center, Sun Yat-sen University, Guangzhou 510060, China
\end{abstract}

Email: Na Wang - wangxiaonaxx@163.com; Qiu-Liang Wu - violet_jj@163.com; Yan Fang - violet_jj@163.com; HaiQiang Mai - hqmai@21cn.com; Mu-Sheng Zeng - violet_jj@163.com; Guo-Ping Shen - apple999spg@hotmail.com; Jing-

Hui Hou - violet_jj@163.com; Yi-Xin Zeng* - yxzeng@gzsums.edu.cn

* Corresponding author

Published: 26 June 2005

Journal of Translational Medicine 2005, 3:26 doi:10.1 186/1479-5876-3-26

Received: 02 May 2005

Accepted: 26 June 2005

This article is available from: http://www.translational-medicine.com/content/3/I/26

(C) 2005 Wang et al; licensee BioMed Central Ltd.

This is an Open Access article distributed under the terms of the Creative Commons Attribution License (http://creativecommons.org/licenses/by/2.0), which permits unrestricted use, distribution, and reproduction in any medium, provided the original work is properly cited.

\section{Introduction}

Nasopharyngeal carcinoma (NPC) is a tumor derived from epithelial cells located in the posterior part of the nasopharynx. The nasopharynx has an abundant supply of regional lymphatic vessels, which drain along the internal jugular vein and the posterior cervical and retropharyngeal chains. As a result, NPC frequently spreads regionally leading to early lymph-node involvement in the neck. Systemic dissemination also occurs more readily than in other head-and-neck cancers, frequently involving bones, lung, and liver [1]. Although the primary tumor is sensitive to radiotherapy, NPC-related deaths occur because of secondary spread of tumor cells. It has been observed that at the time of diagnosis, $60-85 \%$ of NPC 
patients already have clinically detectable metastases in the regional lymph nodes or distant organs such as the lungs and bone [2]. Since there is no effective treatment for NPC at the stage of metastasis, the prognosis remains poor with a 5-year survival around 50\%[3].

The metastatic process results from several sequential steps and represents a highly organized, non-random, organ-selective process [4]. Muller et al [5] found that the chemokine receptor CXCR4 and CCR7 were highly expressed in human malignant breast tumors compared to normal breast tissue. The ligands for these receptors CXCL12 (SDF-1) for CXCR4 and CCL21 for CCR7 exhibit high expression in organs in which breast cancer metastases are often found. The organ tropism of metastatic NPC often recapitulates that observed in malignant breast tumors. In addition, Staller et al [6] observed an inverse correlation between CXCR4 expression and survival in patients with renal cell carcinoma (RCC). They also noted that the von Hippel-Lindau tumor suppressor protein pVHL negatively regulates CXCR4 expression owing to its capacity to target hypoxia-inducible factor (HIF) for degradation under normoxic conditions. The process is suppressed under hypoxic conditions, resulting in HIF-dependent CXCR4 activation. Interestingly, the vHL gene is located at 3p26-3p25. This region displays loss of heterozygosity in NPC and the loss of 3p26-13 has been associated to early events in the carcinogenesis of NPC $[7,8]$.

The chemokine receptor CXCR4 is the only physiological receptor for SDF-1 (a member of the CXC subfamily of chemokines) [9-11]. Chemokines represent a large family of about 50 proteins that modulate cell trafficking and angiogenesis, during infection and inflammation and play a significant role in the tumor microenvironment. [12].

CXCR4 plays a major role in embryogenesis, homeostasis and inflammation and can function as a coreceptor for $\mathrm{T}$ lymphocytotrophic HIV-1 isolates $[13,14]$. CXCR4 is also the only chemokine receptor which mRNA expression is regulated during trophoblast differentiation in vitro [15]. Kobayashi et al reported that CXCR4 was down-regulated during differentiation of viral antigen-specific CD8 (+) T cells and could be used to distinguish subsets of CD8 (+) $\mathrm{T}[16]$.

CXCR4 expression has been reported in several epithelial, mesenchymal and haematopoietic cancers [17]. Recently CXCR4 has been shown to be expressed by tumor cells in breast cancer, non-small cell lung cancer, pancreatic cancer, prostate cancer, thyroid cancer and to play an important role in their metastatic process [5,18-22]. Finally, Xu $\mathrm{Y}$ et al found that CXCR4 was highly expressed in NPC cell lines, and its expression was associated with differentiation grade and proliferation ability of NPC cells [23].

Therefore, we asked whether CXCR4 expression is associated with the prognosis and differentiation of NPC. Considering its potential effect on the development of metastases, we investigated the expression of CXCR4 in NPC tissue by immunohistochemistry and observed that high CXCR4 expression is associated with poor survival independently of the differentiation status in NPC.

\section{Materials and methods \\ Reagents and antibodies}

The anti-CXCR4 mouse monoclonal antibody (MAB 172; R\&D Systems; dilution 1:600) was used for immunohistochemical analysis. The PV-9000 Polymer Detection System was used for immunohistochemical staining according to the manufacturer's recommendations (Golden Bridge International, USA).

\section{Nasopharyngeal carcinoma tissues}

Immunohistochemistry was performed on undifferentiated NPC carcinomas tissues collected from 194 patients who were admitted to the Sun Yat-sen University Cancer Center in the year 2000 and could be followed for three years until 2004. We also analyzed 26 NPC tissue samples of different histological subtype containing 10 undifferentiated carcinomas, 10 differentiated carcinomas and 6 keratinising squamous cell carcinomas from these patients admitted to the center from 2000 to 2004. All samples were obtained with full patient consent.

\section{Immunohistochemical analysis}

Samples were fixed in $4 \%$ paraformaldehyde or $10 \%$ formalin and embedded in paraffin. Four mm sections were cut and placed on silane-coated slides for immunohistochemical studies. Part of the specimens was stained with $H \& E$ and microscopically examined to confirm the diagnosis. The paraffin sections were dewaxed and pretreated in $0.01 \mathrm{M}$ sodium citrate buffer ( $\mathrm{pH} \mathrm{6.0)}$ for $15 \mathrm{~min}$ at $95^{\circ} \mathrm{C}$ to unmask tissue antigen. These sections were then incubated with $3 \%$ hydrogen peroxide for 30 minutes at room temperature to block endogenous peroxidase. Immunostaining was performed with anti-CXCR4 antibody (dilution 1:600) at $4^{\circ} \mathrm{C}$ overnight. The sections were developed according to manufacturer's recommendations (PV-9000 Polymer Detection System, Golden Bridge International, USA) and counterstained with hematoxylin. CXCR4 positivity was graded semiquantitatively according to Carcangiu's method[24] as negative or weak (total score $\leq 3$ ) and positive (total score $\geq 4$ ) by two independent investigators without knowledge of the patients' clinicopathological features and the clinical follow-up data. 


\section{Statistical analysis}

Survival was calculated by the Kaplan-Meier method, and the resulting curves were compared using the log-rank test. Fisher's exact test and the $\chi^{2}$ test were used to analyze the association between two categorical variables. $P<0.05$ was considered to be statistically significant.

\section{Results \\ Expression pattern of CXCR4 in nasopharyngeal carcinoma}

We first examined 194 NPC cases for which three-year follow up information was available. All the tumors were pathologically classified as WHO type III (undifferentiated carcinoma). We observed different staining patterns of CXCR4 in NPC tumor cells: 135 showed nucleus staining, 18 nucleus and cytoplasm staining, 2 nucleus and cytoplasm and membrane staining, 14 cytoplasm staining, 22 cytoplasm and membrane staining, 2 membrane staining and one negative staining (Fig. 1, C, D and 1E). Since positive nucleus staining was the most frequently observed pattern, we examined whether there was a correlation between positive nucleus staining and survival by dividing samples into two categories according to positive or negative nuclear staining. No statistically significant correlation was noted with survival. In addition, nuclear staining was not related to intensity of staining.

Intensity of staining was also observed to be variable among samples ranging from absent or weak to strong (Fig. 1, C, D, E). The non-cancerous nasopharyngeal epidermis stained either weakly or not at all (Fig. 1, B). Strong CXCR4 expression was detected in 45.4\% (88/ 194) of the cancerous samples while the remaining displayed weak (105 samples) or negative (1 sample) staining. Among the samples with strong CXCR4 expression 67 showed nuclear staining, 2 nuclear and cytoplasm staining, 6 cytoplasm staining, 11 cytoplasm and membrane staining, and 2 membrane staining. The distribution of the CXCR4 staining is summarized in Table 1.

\section{CXCR4 expression is correlated with metastatization and tumor-specific survival}

Next, we analyzed the relationship between distant metastases and CXCR4 staining. Metastatic rate was significantly higher in patients with strong CXCR4 (38.6\%) compared to weak or absent $(19.8 \%)$ staining $(P=0.004$; Table 2$)$. Distant metastatic sites included lungs, brain, liver and bone.

We further analyzed the intensity of CXCR4 staining in relation with patient survival at 3 years follow up. During this period, 28.4\% (55/194) patients experience metastatic recurrence and the overall survival (OS) was 75.3\% (146/194), expectedly higher than the reported 5-year survival rate for NPC [3]. Strong CXCR4 staining was associ- ated with poor survival $(\mathrm{OS}=67.05 \%$ versus $82.08 \%, P=$ 0.03 ) (Fig. 2) while no correlation was observed between level of CXCR4 expression and age, gender, or tumor stages (Table 2).

\section{Expression of CXCR4 is not related to the status of differentiation of NPC}

CXCR4 has been reported to be involved in NPC cells differentiation [23]. Most NPC in high risk areas belong to WHO type III (undifferentiated carcinoma) while the more differentiated type, keratinising squamous cell carcinoma, and the differentiated carcinoma are rarely observed. To examine if CXCR4 expression is influenced by the differentiation status in NPC, we collected 26 NPC samples consisting of 6 keratinising squamous cell carcinomas, 10 differentiated carcinomas and 10 undifferentiated carcinomas. Different staining patterns consisted of 3 nuclear, 2 nuclear and cytoplasm, 13 nuclear, cytoplasm and membrane, 6 cytoplasm and 2 cytoplasm and membrane staining (Figure 1, F). The distributing of the CXCR4 location is summarized in Table 3. There was no correlation between staining location and differentiation status of the NPC samples. In addition, 34.6\% (9/26) samples stained strongly while the other 17 samples stained weakly with no correlation with differentiation status.

\section{Discussion}

The chemokine receptor CXCR4 is the only physiological receptor for SDF-1. SDF-1/CXCR4 interactions have been intensively investigated in immunology, especially with regard to mechanism of HIV-1 infection to T lymphocytes $[13,14]$. Recently attention was turned to its involvement in cancer development and progression. Balkwill [17] reviewed that malignant cells from different types of cancer expressed CXCR4 and interact with its ligand SDF-1. Several other studies on breast, lung, pancreatic, prostate and thyroid cancer, and glioma suggested a role of CXCR4 in the metastasatic process [5,18-22].

In the present study, we evaluated CXCR4 expression in nasopharyngeal carcinoma by immunohistochemistry. The observed association between strong CXCR4 expression and poor tumor-specific survival suggests that CXCR4 expression levels influence the metastatic behavior of NPC. Among the known factors associated with NPC induction, Epstein-Barr virus (EBV) infection plays an important role. Latent membrane protein (LMP)- 1 is the EBV-encoded protein with the most significant oncogenic properties. In addition, LMP-1 induces NF- $\mathrm{BB}$ activation which has important effects on EBV-infected cell survival [25]. NF- $\kappa \mathrm{B}$, in turn, regulates the motility of breast cancer cells by directly up-regulating the expression of CXCR4. Over expression of the inhibitor of NF- $\kappa B$ (I $\mathrm{B}$ ) in breast cancer cells constitutively expressing NF- $\kappa \mathrm{B}$ 

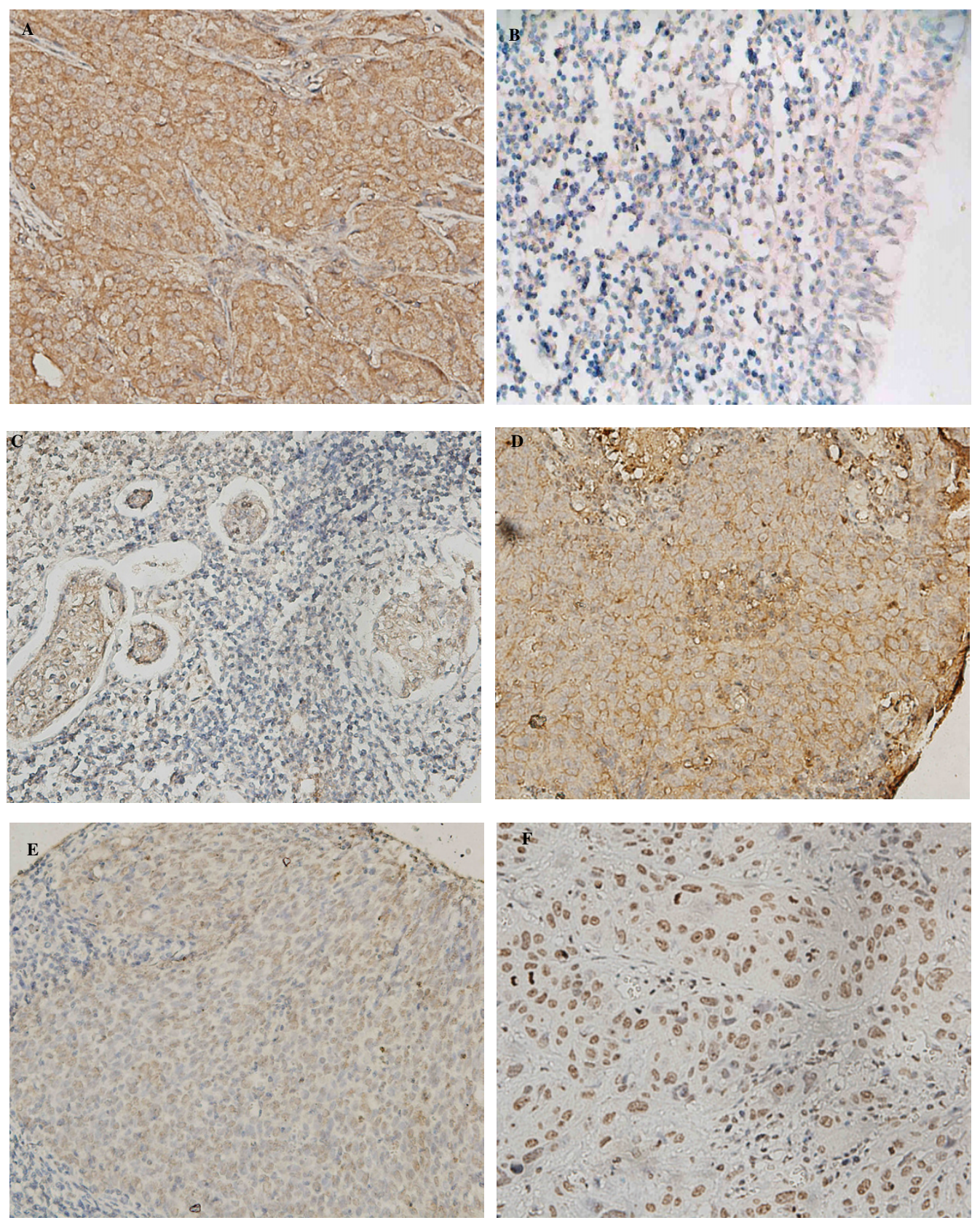

\section{Figure I}

Immunohistochemical evaluation of CXCR4 expression. (A) Cytoplasm and membrane staining in a breast cancer tissue as a positive control. (B) Weak or absent staining in a normal nasopharyngeal epidermis. (C) An undifferentiated nasopharyngeal carcinoma of cytoplasm staining with adjacent lymphocytes displaying predominant cytoplasmic staining. (D) An undifferentiated nasopharyngeal carcinoma of membrane staining. (E) An undifferentiated nasopharyngeal carcinoma of nucleus staining. (F) Representative nucleus staining in a keratinising squamous cell carcinoma of nasopharynx. (All of the photomicrographs are high-powered magnified, $\times 400)$. 
Table I: Staining location of CXCR4 in the 194 undifferentiated nasopharyngeal carcinomas

\begin{tabular}{ccccccc}
\hline $\begin{array}{c}\text { Expression } \\
\text { Pattern Total } \\
(\mathrm{n}=194)\end{array}$ & $\begin{array}{c}\text { Nucleus } \\
\text { staining }\end{array}$ & $\begin{array}{c}\text { Nucleus and } \\
\text { cytoplasm } \\
\text { staining }\end{array}$ & $\begin{array}{c}\text { Nucleus and } \\
\text { cytoplasm } \\
\text { and membrane } \\
\text { staining }\end{array}$ & $\begin{array}{c}\text { Cytoplasm } \\
\text { staining }\end{array}$ & $\begin{array}{c}\text { Cytoplasm } \\
\text { and } \\
\text { membrane } \\
\text { staining }\end{array}$ & $\begin{array}{c}\text { Membrane } \\
\text { staining }\end{array}$ \\
$\begin{array}{c}\text { Absent } \\
\text { staining }\end{array}$ \\
Strong staining $(\mathrm{n}=88)$ & 67 & 2 & 0 & 6 & 11 & 2 \\
Weak or absent staining $(\mathrm{n}=106)$ & 68 & 16 & 2 & 8 & 11 & 0 \\
\hline
\end{tabular}

Table 2: Staining intensity of CXCR4 and clinical characteristics of NPC patients

\begin{tabular}{|c|c|c|c|c|}
\hline Characteristics & Strong staining $(\mathrm{n}=88)$ & Weak or absent staining $(n=106)$ & Total $(n=194)$ & $P$ \\
\hline \multicolumn{5}{|l|}{ Age } \\
\hline Median (range) & $45(25-70)$ & $46(14-72)$ & $45(14-72)$ & \\
\hline$<50$ & 58 & 65 & 123 & 0.408 \\
\hline$\geq 50$ & 30 & 41 & 71 & \\
\hline \multicolumn{5}{|l|}{ Gender } \\
\hline Female & 17 & 27 & 44 & 0.308 \\
\hline Male & 71 & 79 & 150 & \\
\hline \multicolumn{5}{|l|}{ Stage } \\
\hline $\mathrm{I} / \mathrm{II}$ & 21 & 39 & 60 & 0.052 \\
\hline III/IV & 67 & 67 & 134 & \\
\hline \multicolumn{5}{|l|}{$\mathrm{N}$ stage } \\
\hline No & 18 & 25 & 43 & 0.601 \\
\hline non-NO & 70 & 81 & $15 \mid$ & \\
\hline \multicolumn{5}{|c|}{ Metastasis (follow-up) } \\
\hline Yes & 34 & 21 & 55 & 0.004 \\
\hline No & 54 & 85 & 139 & \\
\hline
\end{tabular}

results in reduced expression of CXCR4 and a corresponding loss of SDF- $1 \alpha$-mediated migration in vitro [26]. This observation may explain that the correlation between high expression of CXCR4 in NPC cells and metastatic rate in NPC patients which in turn affects their survival.

Our results are consistent with others' recent studies. Murakami et al [27] suggested that a limited number of chemokine receptors might play a critical role in determining organ-tropism in metastatic melanoma by regulating chemoattraction, adhesion, and survival. In particular, they advocated a role for chemokine receptor 7 (CCR7) in lymph node metastasis, CXCR4 in pulmonary metastasis, and CCR10 in skin metastasis. Moreover, CXCR4 expression in neuroblastoma primary tumors is significantly correlated with the pattern of metastatic spread. Similar findings were also reported from investigations on prostate cancer, head and neck squamous cell carcinoma and neuroblastoma primary tumors [28-30]. Furthermore, Lapteva et al found that small interfering RNA (siRNA) against CXCR4 effectively abrogated breast tumor growth in vivo implying CXCR4 as potential target to control breast cancer growth and metastasis [31].
We noted distinct patterns of CXCR4 staining in NPC tissues including nuclear, membrane and cytoplasm (Figure 1). CXCR4 is a serpentine transmembrane protein that mediates signal transduction according to its location on the cell membrane or in the cytoplasm. In this study, we observed a high percentage of nuclear staining of CXCR4. Three previous studies also identified nuclear localization of CXCR4 in hepatocellular carcinoma [32], invasive ductal mammary carcinoma [33] and non-small-cell lung cancer (NSCLC) [19]. Kato et al [33] reported nuclear staining of CXCR4 and defined the expression pattern of CXCR4 as diffuse or focal observing a significant correlation with the rate of lymph node metastases in breast cancers. Spano et al [19] found that strong CXCR4-nuclear staining was associated with significantly better outcome in early-stage NSCLC. However, we could not correlate nuclear staining with clinical outcome. This inconsistency of our findings with others' reports may be the result of the different tissue types studied and larger studies will be required to draw definitive conclusions.

To test whether a relationship exists between CXCR4 expression and differentiation of NPC, as reported by Xu 


\section{Survival Functions}

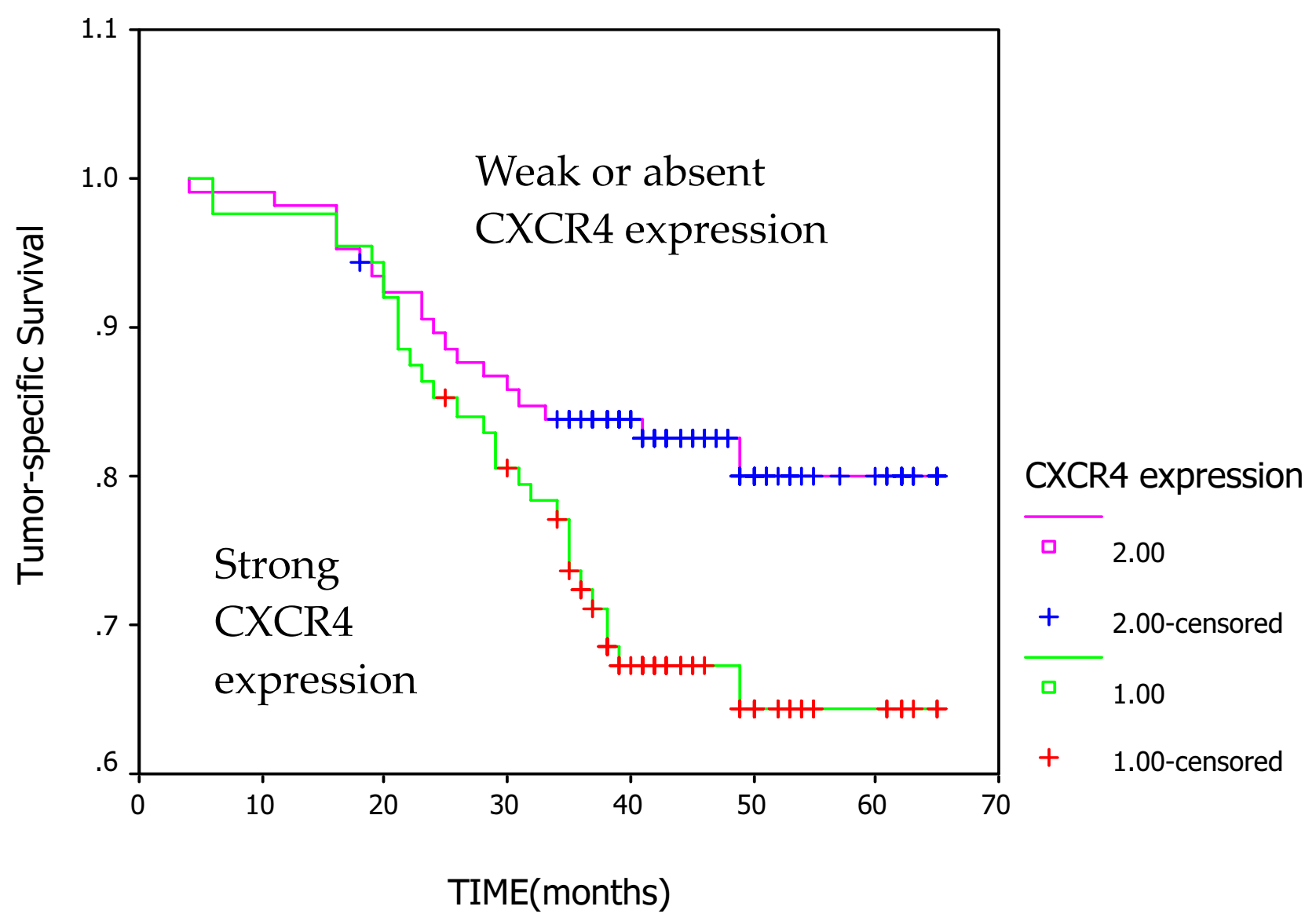

Figure 2

Kaplan-Meier analysis of tumor-specific survival in patients with NPC according to CXCR4 expression. Strong staining was associated with poor survival compared with weak or absent expression $(O S=67.05 \%$ versus $82.08 \%, P=0.0225)$.

et al [23], we collected another 26 NPC samples with different differentiation status. As shown in Table 3, we did not observe a correlation. Such correlation was also not fund in other solid tumor cells.

In summary, our results identified an aberrant expression of CXCR4 in NPC cells and the high level of CXCR4 expression correlated with distant metastasis and poor tumor-specific survival. These results further imply that CXCR4 could be involved in NPC progression and strong staining of CXCR4 could be used as a predictor for NPC prognosis.

\section{Authors' contributions}

Yi-Xin Zeng is the general supervisor of the research group. He made substantial contributions to conception and designed the experiments, gave final approval of the version to be submitted.

Na Wang made fundamental contributions to this article. She completed most of the experiments, analysised the results and drafted this article.

Qiu-Liang $\mathrm{Wu}$ performed the evaluation of CXCR4 positivity. 
Table 3: Staining location and intensity of CXCR4 in 26 NPC samples with different differentiation status

\begin{tabular}{|c|c|c|c|c|c|c|}
\hline $\begin{array}{l}\text { Expression } \\
\text { Pattern Total } \\
(n=26)\end{array}$ & & $\begin{array}{l}\text { Nucleus } \\
\text { staining }\end{array}$ & $\begin{array}{c}\text { Nucleus and } \\
\text { cytoplasm staining }\end{array}$ & $\begin{array}{c}\text { Nucleus and } \\
\text { cytoplasm } \\
\text { and membrane } \\
\text { staining }\end{array}$ & $\begin{array}{l}\text { Cytoplasm } \\
\text { staining }\end{array}$ & $\begin{array}{c}\text { Cytoplasm and } \\
\text { membrane staining }\end{array}$ \\
\hline & $\begin{array}{c}\text { Keratinising } \\
\text { squamous cell } \\
\text { Carcinoma }(n=3)\end{array}$ & 3 & 0 & 0 & 0 & 0 \\
\hline \multirow[t]{3}{*}{ Strong staining $(n=9)$} & $\begin{array}{c}\text { Differentiated } \\
\text { carcinomas }(n=4)\end{array}$ & 0 & 0 & 1 & 2 & 1 \\
\hline & $\begin{array}{l}\text { Undifferentiated } \\
\text { carcinomas }(n=2)\end{array}$ & 0 & 0 & 2 & 0 & 0 \\
\hline & $\begin{array}{c}\text { Keratinising } \\
\text { squamous cell } \\
\text { Carcinoma }(n=3)\end{array}$ & 0 & 1 & 2 & 0 & 0 \\
\hline \multirow[t]{2}{*}{ Weak staining $(n=17)$} & $\begin{array}{c}\text { Differentiated } \\
\text { carcinomas }(n=6)\end{array}$ & 0 & 0 & 2 & 3 & 1 \\
\hline & $\begin{array}{l}\text { Undifferentiated } \\
\text { carcinomas }(n=8)\end{array}$ & 0 & 1 & 6 & 1 & 0 \\
\hline
\end{tabular}

Yan Fang made the tissue microarray and provided part of the samples.

Hai-Qiang Mai collected the other part of the samples.

Mu-Sheng Zeng helped to design the experiments.

Guo-Ping Shen performed the statistical analysis.

Jing-Hui Hou helped to do the experiments.

\section{References}

I. Vokes EE, Liebowitz DN, Weichselbaum RR: Nasopharyngeal carcinoma. Lancet 1997, 350(9084): 1087-1091.

2. Hu LF, Chen F, Zheng X, Ernberg I, Cao SL, Christensson B, Klein G, Winberg G: Clonability and tumorigenicity of human epithelial cells expressing the EBV encoded membrane protein LMPI. Oncogene 1993, 8(6):1575-1583.

3. Li XP, Li G, Peng Y, Kung HF, Lin MC: Suppression of EpsteinBarr virus-encoded latent membrane protein-I by RNA interference inhibits the metastatic potential of nasopharyngeal carcinoma cells. Biochem Biophys Res Commun 2004, $3|5(1): 2| 2-2 \mid 8$.

4. Nicolson GL: Paracrine and autocrine growth mechanisms in tumor metastasis to specific sites with particular emphasis on brain and lung metastasis. Cancer Metastasis Rev 1993, I 2(34):325-343.

5. Muller A, Homey B, Soto H, Ge N, Catron D, Buchanan ME, McClanahan T, Murphy E, Yuan W, Wagner SN, Barrera JL, Mohar A, Verastegui E, Zlotnik A: Involvement of chemokine receptors in breast cancer metastasis. Nature 200I, 4I 0(6824):50-56.

6. Staller P, Sulitkova J, Lisztwan J, Moch H, Oakeley EJ, Krek W: Chemokine receptor CXCR4 downregulated by von Hippel-Lindau tumour suppressor pVHL. Nature 2003, 425(6955):307-3II.

7. Deng L, Jing N, Tan G, Zhou M, Zhan F, Xie Y, Cao L, Li G: common region of allelic loss on chromosome region 3p25.3-26.3 in nasopharyngeal carcinoma. Genes Chromosomes Cancer 1998, 23(I):2I-25.

8. Huang Z, Desper R, Schaffer AA, Yin Z, Li X, Yao K: Construction of tree models for pathogenesis of nasopharyngeal carcinoma. Genes Chromosomes Cancer 2004, 40(4):307-3I 5.

9. Rollins BJ: Chemokines. Blood 1997, 90(3):909-928.
10. Rossi D, Zlotnik A: The biology of chemokines and their receptors. Annu Rev Immunol 2000, I 8:2 I7-242.

II. Zlotnik A, Yoshie O: Chemokines: a new classification system and their role in immunity. Immunity 2000, I2(2): I2I-127.

12. Vicari AP, Caux C: Chemokines in cancer. Cytokine Growth Factor Rev 2002, I3(2): | 143-154.

13. Feng Y, Broder CC, Kennedy PE, Berger EA: HIV-I entry cofactor: functional cDNA cloning of a seven-transmembrane, $G$ protein-coupled receptor. Science 1996, 272(5263):872-877.

14. Bleul CC, Farzan M, Choe H, Parolin C, Clark-Lewis I, Sodroski J, Springer TA: The lymphocyte chemoattractant SDF-I is a ligand for LESTR/fusin and blocks HIV-I entry. Nature 1996, 382(6594):829-833.

15. Jaleel MA, Tsai AC, Sarkar S, Freedman PV, Rubin LP: Stromal cellderived factor-I (SDF-I) signalling regulates human placental trophoblast cell survival. Mol Hum Reprod 2004, I0(12):90I-909.

16. Kobayashi N, Takata H, Yokota S, Takiguchi M: Down-regulation of CXCR4 expression on human CD8+ $T$ cells during peripheral differentiation. Eur J Immunol 2004, 34(I 2):3370-3378.

17. Balkwill $F$ : The significance of cancer cell expression of the chemokine receptor CXCR4. Semin Cancer Biol 2004, I4(3): I7I-179.

18. Koshiba T, Hosotani R, Miyamoto $\mathrm{Y}$, Ida J, Tsuji S, Nakajima S, Kawaguchi M, Kobayashi H, Doi R, Hori T, Fujii N, Imamura M: Expression of stromal cell-derived factor I and CXCR4 ligand receptor system in pancreatic cancer: a possible role for tumor progression. Clin Cancer Res 2000, 6(9):3530-3535.

19. Spano JP, Andre F, Morat L, Sabatier L, Besse B, Combadiere C, Deterre P, Martin A, Azorin J, Valeyre D, Khayat D, Le Chevalier T, Soria JC: Chemokine receptor CXCR4 and early-stage nonsmall cell lung cancer: pattern of expression and correlation with outcome. Ann Oncol 2004, 15(4):613-617.

20. Taichman RS, Cooper C, Keller ET, Pienta KJ, Taichman NS, McCauley LK: Use of the stromal cell-derived factor-I/CXCR4 pathway in prostate cancer metastasis to bone. Cancer Res 2002, 62(6): $1832-1837$.

2I. Hwang JH, Hwang JH, Chung HK, Kim DW, Hwang ES, Suh JM, Kim H, You KH, Kwon OY, Ro HK, Jo DY, Shong M: CXC chemokine receptor 4 expression and function in human anaplastic thyroid cancer cells. J Clin Endocrinol Metab 2003, 88(I):408-4I6.

22. Zhou $\mathrm{Y}$, Larsen PH, Hao C, Yong VW: CXCR4 is a major chemokine receptor on glioma cells and mediates their survival. J Biol Chem 2002, 277(5 I):4948I-49487.

23. Xu Y, Zhang SZ, Huang PC, Chen J, Cai KR: Expression of chemokine receptor CXCR4 in nasopharyngeal carcinoma cells. Ai Zheng 2004, 23(2): I36-I 40. 
24. Carcangiu ML, Chambers JT, Voynick IM, Pirro M, Schwartz PE: Immunohistochemical evaluation of estrogen and progesterone receptor content in $\mathbf{1 8 3}$ patients with endometrial carcinoma. Part I: Clinical and histologic correlations. Am J Clin Pathol 1990, 94(3):247-254.

25. Luftig M, Yasui T, Soni V, Kang MS, Jacobson N, Cahir-McFarland E, Seed B, Kieff E: Epstein-Barr virus latent infection membrane protein I TRAF-binding site induces NIK/IKK alpha-dependent noncanonical NF-kappaB activation. Proc Natl Acad Sci 2004, I0I(I): |4I-I 46.

26. Helbig G, Christopherson KW 2nd, Bhat-Nakshatri P, Kumar S, Kishimoto H, Miller KD, Broxmeyer HE, Nakshatri H: NF-kappaB promotes breast cancer cell migration and metastasis by inducing the expression of the chemokine receptor CXCR4. J Biol Chem 2003, 278(24):2163|-21638.

27. Murakami T, Cardones AR, Hwang ST: Chemokine receptors and melanoma metastasis. J Dermatol Sci 2004, 36(2):7I-78.

28. Singh S, Singh UP, Grizzle WE, Lillard JW Jr: CXCLI 2-CXCR4 interactions modulate prostate cancer cell migration, metalloproteinase expression and invasion. Lab Invest 2004, 84(12): 1666-1676.

29. Samara GJ, Lawrence DM, Chiarelli CJ, Valentino MD, Lyubsky S, Zucker S, Vaday GG: CXCR4-mediated adhesion and MMP-9 secretion in head and neck squamous cell carcinoma. Cancer Lett 2004, 2 I 4(2):23I-24I.

30. Russell HV, Hicks J, Okcu MF, Nuchtern JG: CXCR4 expression in neuroblastoma primary tumors is associated with clinical presentation of bone and bone marrow metastases. J Pediatr Surg 2004, 39(10): I506-15II.

31. Lapteva N, Yang AG, Sanders DE, Strube RW, Chen SY: CXCR4 knockdown by small interfering RNA abrogates breast tumor growth in vivo. Cancer Gene Ther 2005, I 2(1):84-89.

32. Shibuta K, Mori M, Shimoda K, Inoue H, Mitra P, Barnard GF: Regional expression of CXCLI 2/CXCR4 in liver and hepatocellular carcinoma and cell-cycle variation during in vitro differentiation. Jpn J Cancer Res 2002, 93(7):789-797.

33. Kato M, Kitayama J, Kazama S, Nagawa $\mathrm{H}$ : Expression pattern of CXC chemokine receptor-4 is correlated with lymph node metastasis in human invasive ductal carcinoma. Breast Cancer Res 2003, 5(5):RI44-50.

Publish with Biomed Central and every scientist can read your work free of charge

"BioMed Central will be the most significant development for disseminating the results of biomedical research in our lifetime. "

Sir Paul Nurse, Cancer Research UK

Your research papers will be:

- available free of charge to the entire biomedical community

- peer reviewed and published immediately upon acceptance

- cited in PubMed and archived on PubMed Central

- yours - you keep the copyright
BioMedcentral 